Revista de la red interuniversitaria de estudios sobre las literaturas rioplatenses contemporáneas en Francia

23 | 2021

La vereda de enfrente. Cruces entre las literaturas argentina y chilena del siglo XX

\title{
Comunidad trasandina en la década de los setenta: Hector Libertella y Enrique Lihn
}

Communauté transandine dans les années 1970 : Hector Libertella et Enrique Lihn

Trans-Andean Community in the 1970s: Hector Libertella and Enrique Lihn

\section{Francisca Lange V.}

\section{(2) OpenEdition}

\section{Journals}

Edición electrónica

URL: https://journals.openedition.org/lirico/11454

DOI: $10.4000 /$ lirico. 11454

ISSN: 2262-8339

Editor

Réseau interuniversitaire d'étude des littératures contemporaines du Río de la Plata

Referencia electrónica

Francisca Lange V., «Comunidad trasandina en la década de los setenta: Hector Libertella y Enrique Lihn», Cuadernos LIRICO [En línea], 23 | 2021, Publicado el 09 diciembre 2021, consultado el 07 enero 2022. URL: http://journals.openedition.org/lirico/11454 ; DOI: https://doi.org/10.4000/lirico.11454

Este documento fue generado automáticamente el 7 enero 2022.

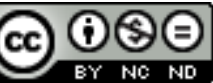

Cuadernos LIRICO está distribuido bajo una Licencia Creative Commons Atribución-NoComercialSinDerivar 4.0 Internacional. 


\title{
Comunidad trasandina en la década de los setenta: Hector Libertella y Enrique Lihn
}

\author{
Communauté transandine dans les années 1970 : Hector Libertella et Enrique
}

Lihn

Trans-Andean Community in the 1970s: Hector Libertella and Enrique Lihn

Francisca Lange V.

\section{Introducción}

1 En 1977 el argentino Héctor Libertella publica Nueva Escritura en Latinoamérica, su primer libro de carácter ensayístico ${ }^{1}$, cuya propuesta teórico-crítica resulta singular en esa década, más aún si se considera el contexto cultural, económico y político de Latinoamérica. El libro genera polémica cuando Emir Rodríguez Monegal, voz autorizada de la crítica académica, publica en la revista Vuelta (1978) una reseña donde pone en tela de juicio los objetivos y la trama teórico-crítica que construye el argentino. Para el crítico uruguayo, no es más que una apuesta arrogante, que intenta ser vanguardista de la mano de las lecturas del postestructuralismo francés, pero que carece del carácter novedoso y que sólo construye un canon a lo menos antojadizo ${ }^{2}$. El desdén alcanza incluso a la editorial que publica el libro, la venezolana Monte Ávila, cuya seriedad y prestigio se había construido sobre un catálogo donde destacaban nombres como los de Adorno, Barthes, Benjamin, Frye, Guillermo Sucre o Julio Ortega. Para Rodríguez Monegal la decisión de publicar a Libertella resulta ser "una lástima, porque el discurso crítico sobre la nueva narrativa latinoamericana no puede adelantar con trabajos de este tipo: malinformados, tendenciosos, ingeniosos, acríticos" (citado en Pardo 2014: 69). Un año después, el autor de Nueva Escritura en Latinoamérica va a responder a aquella arremetida en las páginas de la misma revista, donde señala que el 
libro "se armó, en fin, como una propuesta o gesto crítico salido de la literatura para devolverse a ella" (citado en Pardo 2014: 70).

Lamborghini, Elizondo, Sarduy, Puig, Arenas y Lihn son los autores de las novelas comentadas en el libro que, efectivamente, se aleja del discurso académico que defiende Rodríguez Monegal. La cercanía de la escritura de Libertella con lo que Raúl Antelo llama "el pensamiento del 68" (2010: 149), pone en diálogo ese trabajo con aquellas lecturas que se cuestionan la relación forma y fondo, sujeto y existencia en el arte, y que empiezan a despuntar, principalmente, a partir de la filosofía francesa de postguerra. De este modo, lo que impugna Rodríguez Monegal apunta a la falta de novedad de esa tendencia en la crítica Latinoamericana, a la escasa rigurosidad en su aplicación y al corpus antojadizo que presenta el libro.

En Chile, el citado Lihn comenta el trabajo de Libertella en su ensayo "Entretelones técnicos de mis novelas" (1981), que oficia de introducción a un dossier fabricado por el mismo autor, fotocopiado y entregado a algunxs amigxs y lectorxs. Este compilado no tiene intención comercial y, además del citado artículo, contiene borradores, fragmentos de su poesía, imágenes del book action Lihn \& Pompier, entrevistas, apuntes, cartas. La condición artesanal de este trabajo revela su carácter transitorio, perecible, inédito, en cada vuelta de página, donde accedemos a partes de una travesía en la cual el autor cuestiona su condición autoral y despliega una escritura autorreflexiva y transdiciplinaria.

4 Si se leen en conjunto las propuestas de Lihn y de Libertella, la crítica de Rodríguez Monegal, por contraste, permite dar cuenta de algunos elementos propios del campo cultural latinoamericano de las décadas de los sesenta y setenta. A diferencia de Rodríguez Monegal, Lihn y Libertella son disidentes de los cánones de la época, en la cual predomina la "convicción de una identidad común" e incluso la existencia de "una familia intelectual latinoamericana", tal y como sostiene Claudia Gilman en su libro Entre la pluma y el fusil (2012: 102), cuya existencia está articulada sobre la necesidad de una serie de intereses y proyectos colectivos.

5 Frente a ese imperativo de lo común, un tipo de comunidad orgánica, los trabajos de Lihn y Libertella avanzan por otro carril, que dialoga con las nociones de comunidad inoperante y comunismo literario que desarrolla Jean Luc Nancy. Este diálogo se presenta en la lectura que ambos autores hacen sobre entorno y tradiciones culturales así como en sus escrituras, que son disidentes y al mismo tiempo parte del campo cultural tercermundista. Es a partir de estas distinciones que se organiza el presente artículo.

\section{Revolución, boom y la ilusión de lo común}

El campo cultural latinoamericano de los años sesenta y setenta está marcado por dos acontecimientos, la revolución cubana y el boom literario.

7 La influencias y efectos de la revolución cubana se inscriben en un contexto internacional donde la política resulta ser un eje indispensable para las producciones textuales y estéticas de la época, ya sea a través de la creación de discursos donde la relación arte y política es fundamental, ya sea por oposición a éste o por omisión. Por otra parte, la publicación de Cien años de soledad en 1967 se convierte en un fenómeno 
universal, lo que anuncia la apertura del campo editorial a la literatura latinoamericana así como un discurso en el cual se afianza este campo intelectual.

Dicho lo anterior, uno de los fenómenos importantes de esa época es la búsqueda de nuevos espacios de intervención, lo que determina a su vez una expansión de nuevos lenguajes del público lector. En este contexto, las revistas político-culturales ocupan un lugar fundamental, como señala Gilman, "[constituyeron] un modo de intervención especialmente adecuado a los perfiles de esa década y de la relación programáticamente buscada entre cultura y política como un modo de pensar la militancia en el plano cultural" (2012: 77).

Las revistas y una serie de encuentros, jornadas y congresos ocurridos en estas décadas dan cuenta de la búsqueda de elementos literarios y culturales en común que permitieron configurar el espacio literatura latinoamericana, que aspiraba a romper con las clasificaciones de las literaturas nacionales. La circulación y lectura de la novela de García Márquez es posible gracias a la presentación y comentarios que realiza Ángel Rama en la revista Marcha, así como a la circulación de borradores y fragmentos entre críticos, editores y escritores para llegar a convertirse en una obra que será leída como el modelo de la ficción latinoamericana.

10 Tanto la recepción y circulación de Cien años de soledad, la reunión de escritores en distintos eventos institucionales, así como la creación de revistas, manifiestan una dinámica que genera una comunidad intelectual que es al mismo tiempo una comunidad afectiva ${ }^{3}$. Me interesa destacar, en consonancia con la propuesta de Gilman, que la conformación de la comunidad intelectual latinoamericana se produce en este cruce de relaciones, y esto es así en la medida que escritoras y escritores buscan conocerse, conocer las obras escritas fuera de los ejes nacionales, movilizadas y movilizados por el descubrimiento de una identidad y un proyecto en común que vaya más allá del campo cultural (2012: 103-104). Esta última premisa es la que va a generar distintos quiebres. Un ejemplo ilustrativo es la polémica suscitada a propósito de la publicación de la revista Mundo Nuevo, dirigida por Emir Rodríguez Monegal.

11 Esta polémica, que ocurre en 1966, es encabezada por Ángel Rama y el mismo Rodríguez Monegal a través de una serie de cartas que son publicadas en Marcha, dirigida por Rama, y otras revistas de la misma línea. Un argumento fundamental de la disputa es el financiamiento de la revista que se adjudica a fundaciones estadounidenses relacionadas con la CIA. El otro, es su espíritu abierto y modernizador que se manifiesta en la invitación y publicación de escritoras y escritores no latinoamericanos, así como tampoco relacionados con el proyecto emancipador y revolucionario propiciado por la revolución.

12 La discusión sobre lo que es o debe ser la literatura latinoamericana da cuenta de tensiones ideológicas y estéticas articuladas por la relación literatura-política y por lo que Idelber Avelar denomina "voluntad de modernidad" (2000: 41), al sistematizar y reflexionar sobre las condiciones de posibilidad del boom literario y que da cuenta de sus cruces con la publicación de Cien años de soledad.

13 El espíritu modernizador que plantea Avelar dice relación con esa ilusión de lo nuevo, una forma de constituirse como latinoamericano, o lo latinoamericano, mediante un trabajo discursivo que confiere una nueva estética, que da cuenta de la sofisticación y expansión del campo intelectual del continente. Esta construcción no siempre sigue los cánones de la revolución política. Si bien algunos de los autores clasificados en este movimiento apoyaron abiertamente el proceso político cubano y sus derivas en el 
subcontinente, como el mismo García Márquez o Cortázar, el boom se conoce sobre todo como un fenómeno editorial y comercial que, sin embargo, ofrece nuevos modos de escritura y formación discursiva anclados en la noción de lo moderno y, por lo tanto, en la promesa de una "nueva ficción".

\section{La ruptura de la familia}

En 1971 se produce una división importante en la familia intelectual latinoamericana, como la llama Gilman, con la irrupción del caso Padilla, que consiste en la acusación al poeta Heberto Padilla de actividades contrarrevolucionarias tras una breve pero intensa polémica sobre la condición de poeta revolucionario y la de contrarevolucionario, la que años antes lo había enfrentado a Guillermo Cabrera Infante. El poeta es encarcelado luego de la lectura pública de un poema donde insinúa críticas al régimen castrista $\mathrm{y}$, tras un mes en prisión, decide presentar disculpas públicas.

Tanto su encarcelamiento como su mea culpa generan una fractura en la intelectualidad latinoamericana, y visibiliza un conflicto latente descrito por Nicolás Casullo en estos términos: "esa tensión conflictiva y semitapiada entre el proyecto y 'eso real existente'. Entre las ideas y “esas políticas fácticas. Entre radicalidad teórica y sociedad a la vista" (Casullo 2005: 86).

Las reacciones frente al acontecimiento son inmediatas: cuando el poeta es detenido, cincuenta y cuatro intelectuales, cubanos y extranjeros, firman una carta dirigida a Fidel Castro donde dan cuenta de su preocupación por la posibilidad de que este evento significara "la reaparición de un proceso de sectarismo" (Gilman 2012: 240). Después de esta primera carta, redactada por Juan Goytisolo y Julio Cortázar, Padilla publica una autocrítica donde se retracta de su posición inicial. Varios de estos intelectuales escriben una segunda carta, en la cual, entre otras cosas sostienen con certeza que esa declaración del escritor cubano fue obtenida mediante algún tipo de tortura. En esta segunda carta no firman Cortázar y García Márquez. Vargas Llosa firma ambas y renuncia al Comité de Colaboración de Casa de las Américas.

En Chile, el impacto de este caso es importante, entre otras cosas, porque pone de manifiesto no sólo la posición política de muchos escritores, sino que también permite comprender su punto de vista sobre la cultura, la literatura y la escritura, es decir, cómo estas son concebidas dentro de la contingencia revolucionaria, donde destaca la discusión sobre el rol del escritor y del intelectual, más aún, puesto que en el año 1971 en Chile está en pleno desarrollo el programa de la Unidad Popular.

18 La revista Mensaje publica en su número 199 (1971) un dossier sobre el tema, para el cual escriben Enrique Lihn, Germán Marín, Carlos Ossa, Lisandro Otero, Mauricio Wacquez y Cristián Huneeus.

19 Lihn, quien había vivido en Cuba en 1968 tras haber recibido el Premio Casa de las Américas, y que había solidarizado con la causa cubana ${ }^{4}$, escribe un texto punzante en el cual recorre la historia cultural de la revolución cubana a través de su relación con los intelectuales extranjeros, que en un principio fue auspiciosa y positiva, para luego transformarse en una relación absolutamente hostil ante cualquier crítica al proyecto revolucionario. De este manera, tanto al artista como al intelectual se le comienza a exigir un cierto guion de comportamiento y creación revolucionaria, que haga evidente 
su distancia y diferencia con "los intelectuales burgueses, libelistas burgueses y agentes de la CIA", con las "ratas intelectuales" que habrían fingido amistad con la Revolución. La conclusión de Lihn se detiene en el lugar del intelectual en la revolución, no sólo en la cubana, sino también en la chilena, tema que por esos días ronda tanto a él como otro grupo de escritores,

Nos preguntamos por qué, en lugar de abrumar tardíamente a sus intelectuales, la Revolución Cubana no se apoyó en ellos para proyectar y sacar adelante una política cultural adecuada a sus circunstancias, sin recurrir a un verdadero ritual primitivo, hecho de ocultamientos, confesiones y mistificaciones.

La legítima aspiración por parte de una sociedad socialista, de crear un cultura nacional y popular, debe plantearse en otros términos y conforme a otros principios (1971a: 236-237, énfasis añadido).

Esta postura le costará al escritor una serie de críticas y rechazos de parte de la intelectualidad chilena de izquierda. Su postura frente a la situación del intelectual y su relación con la política apela a evitar la masificación populista de la cultura y los lineamientos dictados por entes autoritarios, y a revisar los fundamentos marxistas del proyecto revolucionario, el cubano y también el chileno. El mismo año, Lihn oficia como editor de La cultura en la vía chilena al socialismo, donde incluye su artículo "Política y cultura en una etapa de transición al socialismo". Allí, realiza un análisis de la postura de los intelectuales latinoamericanos en relación a la política cultural cubana, para luego ponderar la particularidad del proyecto chileno en diálogo con sus características culturales. Para Lihn "Se hace cada vez más urgente precisar una política cultural que acompañe, desde adentro, el proceso de cambios revolucionarios que está ocurriendo en Chile, en el camino de una democracia socialista" (1971b: 76).

21 En ambos textos, el autor da cuenta de su profunda certeza sobre la inviabilidad de una entidad común, por lo que su propuesta para la cultura en la vía chilena al socialismo se sostiene sobre la heterogeneidad de discursos. De este modo, se aleja de una visión estalinista de la cultura, así como también del control oligárquico sobre los saberes de distinta índole, tal y como se evidenciaba en las páginas del diario El Mercurio, blanco permanente del escritor.

La heterogeneidad que propone Lihn es sostenida a partir de lo que no es, es decir, es una lectura crítica y una propuesta abierta que carece de institucionalidad, porque precisamente esa heterogeneidad permite la buscada "democracia socialista". Se trata de una utopía que entra en tensión con el proyecto colectivo, puesto que la democracia que propone solo puede existir con la participación de las individualidades. Esta suerte de democracia imposible trastoca el proyecto de un ideal común, de una organización homogénea que permita la realización del ideal revolucionario. La puesta en tensión de esta imposibilidad aparece de manera recurrente en la obra del autor, donde es propuesta, analizada y descompuesta, es decir, aparece como una condición irrevocable de su obra.

24 En "Entretelones técnicos sobre mis novelas", y a propósito de un comentario del crítico Filebo, quien cataloga su trabajo como "escritura corrosiva", Lihn propone lo siguiente:

La definición corresponde muy exactamente a mis propósitos novelescos o escriturales, 'textuales' (ignoro si logrados o malogrados), a mi idea de que la literatura es una política. Dispone de medios propios, inmanentes o consustanciales, de ser política y hacerla. Idea que se contrapone al decreto según el cual el compromiso en literatura consiste en convertirla en mensajes tales o cuales, en 
medio de transporte ideológico -correa transmisora de 'ideas' o consignas siempre cambiantes-. Esto es, en un híbrido que representa mal, en cada caso, a las dos especies de que procede. Modo vicario de hacer, por ejemplo, política; frivolización, muchas veces, del trabajo literario (1981: 6)

Lo corrosivo entonces da cuenta del oxímoron constitutivo de su trabajo que se construye como un ejercicio infinito que articula un modo de comunidad disidente de cualquier intento por crear una comunidad intelectual estática, configurada en torno a la utopía de un ideal en común.

\section{La comunidad sin comunidad}

La noción de comunidad que plantea Jean Luc Nancy es la de una comunidad invisibilizada por el principio occidental humanista, alejada de los discursos singulares que le otorgan a lo literario un carácter moldeable:

Las éticas, las políticas, las filosofías de la comunidad, cuando las había (y siempre las hay, aunque sean reducidas a puras habladurías sobre la fraternidad, o a montajes laboriosos sobre la 'intersubjetividad'), continuaron sus caminos o sus estancamientos humanistas sin sospechar por un minuto que estas voces singulares hablaban de la comunidad, y que hablaban quizá sólo de ella, sin sospechar que una experiencia conocida como 'literaria' o 'estética' estaba en la experiencia de la comunidad, y que se le enfrentaba. (Nancy 2000: 28)

Para Nancy, la lógica de la comunidad inoperante se articula frente a la nostalgia de la comunidad perdida, del mito interrumpido que deviene de la historia de un origen, de un habla original (2000: 81-87), ya sea la religión, el nazismo e, incluso, la democracia (Van Rooden 2011: 86). La comunidad de Nancy es, entonces, la comunidad sin comunidad, la pervivencia de un sinnúmero de singularidades. La singularidad es relevante para pensar esta noción de comunidad en tanto no se opone a la "individualidad" mediante "el ser finito", es decir, no viene de ningún lugar, no significa en sí misma, "[n]o es una obra que resulte de una operación" (Nancy 2000: 55). La singularidad se enlaza con lo inidentificable, no se constituye como sujeto, por lo cual a la singularidad le "ocurre" la comunidad. En otros términos:

comparten el linde o límite que permite articular el espacio, distribuirlo como uso plural, jamás divisible en cuanto propiedad exclusiva. En suma, la comunidad de singularidades constituye una articulación siempre abierta del sentido y de la praxis, que interrumpe el mito de la sociedad y el mito de la comunidad misma en las versiones orgánicas que pretenderían endilgarle un propósito final (Duchesne 2009: 16-17)

La experiencia literaria o estética que despliegan estas voces singulares dan paso a lo que se designa como un "comunismo literario". Lo literario aparece como escritura en tanto existe como praxis de una permanente interrupción, es decir, de lo que existe. Se trata de una comunicación que no representa nada más que un modo de interrupción en el espacio-tiempo indicado por la escritura, que se manifiesta como una interrupción permanente de la ilusión de sentido, de la ilusión de ficción así como también la ilusión de lo real.

La permanente interrupción de la escritura y el llamado comunismo literario se despliegan en una constelación sin bordes, en permanente fragmentación. Dice Nancy:

La comunidad sin comunidad es un por venir, en el sentido en que siempre está viniendo, sin parar, al seno de una colectividad (es porque no deja de venir que resiste sin fin a la propia colectividad y al individuo). Sólo es eso: llegar al límite de 
la comparecencia, a este límite al que estamos en efecto convocados, llamados y enviados -y desde donde somos convocados, llamados y enviados. El llamado que nos convoca, así como el que nos dirigimos, en el límite, unos a otros (es sin duda, de uno a otro, el mismo llamado, y no es el mismo) puede denominarse, a falta de otro nombre mejor, la escritura, o la literatura. Pero ante todo, su esencia no consiste en ser la 'cosa literaria'-la comprendamos como la comprendamos (como arte o como estilo, como producción de textos, como comercio o comunicación del pensamiento y del imaginario, etc.)-, y tampoco consiste en aquello que el vocabulario del "llamado" hace escuchar como la invocación, la proclamación, también la declamación, y la efusión de una subjetividad solemne. Esta esencia no está hecha sino del gesto que interrumpe, de un trazo -de una incisión y/o de una inscripción-, la hechura y la escena del mito (2000: 123-124, énfasis añadido).

Dentro de este horizonte, existe un cruce entre el comunismo literario que piensa Nancy y las propuestas de Lihn y Libertella, en tanto sus escrituras figuran como permanentes interrupciones del lenguaje y del relato, al tiempo que difuminan la frontera crítica-teoría-ficción.

\section{Nueva Escritura o la imposible comunidad.}

La crítica de Rodríguez Monegal a Nueva escritura en Latinoamérica da cuenta de un punto de vista, una tradición y un modo normativo de pensar la literatura latinoamericana que difícilmente lee e incorpora una propuesta como la de Libertella, no por falta de información o capacidades de un crítico reconocido como Rodríguez Monegal, sino porque sale del registro de lo existente y lo posible para el campo cultural que habita el crítico uruguayo.

Nueva escritura en Latinoamérica se ocupa, entre otras cosas, de

denunciar hábitos demasiado persistentes en la tradición cercana: el salto explícito de la cultura a la política (la tajante oposición entre la militancia política y una práctica concebida como bizantina o estéril o secundaria según "urgentes" necesidades del proceso); el sutil recurso a temas políticos y lenguajes de protesta o denuncia que quieren 'expresar' un estado de injusticia o de cambio (1977: 21- 22).

La denuncia que se propone se realiza mediante la propuesta y la diseminación que se desarrollan fuera de los márgenes y la jerarquización con la que operan tanto el Boom como la utopía revolucionaria. Sobre la relación con el boom, Julio Premat aborda el carácter radical del libro, que lo aleja del marco epistemológico de la crítica académica, "pensado en contrapunto al boom y en oposición a cierta doxa dominante (empezando por el libro de Carlos Fuentes, La nueva novela hispanoamericana)" (2021:111).

En esta dirección, Libertella expone variaciones sobre su propuesta:

"Nueva" escritura no ha de ser, aquí, la de los jóvenes: tendrá apenas como referencia una manera de escribir trazada sobre cierta lectura activa de la tradición y asociada al proyecto de la crítica en una convivencia (no explicable por alianzas generacionales) donde la productividad de parte de la ficción tiene su negativo fotográfico en otro tipo de productividad dado por la pesquisa teórica (1977: 10).

La nueva escritura busca abrir un espacio justo ahí donde las categorías binarias del pensamiento moderno se naturalizan como fundantes de la literatura latinoamericana. Esta rebeldía se articula incluso en relación con las vanguardias europeas en tanto la crítica y muchos escritores se conectan con ella de manera directa, sin sospechar de la propia reproducción de sus modos, lo que, para el autor, no es más que la continuación de formas de colonización del "primer mundo": 
En este acto local, hasta la misma aceptación de preocupaciones y temas propios de una vanguardia internacional aparece ya replanteada; la novela socio-moral y la "maldita", el sadismo, toda clase de realismo, desde el "socialista" al "mágico", el recurso a la intertextualidad como modo explícito de trabajo e incluso el respeto teológico por el "significante", son elementos que se trituran en la mirada crítica de la nueva escritura toda vez que ésta busca rozar con la Propuesta (1977: 21). "inconsciente (lo incorpora críticamente) mientras produce (re-inscribe) un nuevo texto donde aquellos elementos aparecen proyectados, aplastados, des-representados" (Libertella 1977: 15). operación metafísica de la crítica-ficción latinoamericana y los juicios de valor que impone el mercado (la buena o mala escritura), herencias del paradigma instalado por el boom.

En este libro, Libertella -tal y como Lihn y los autores de las novelas que analizaensaya una mezcla con la cual sea posible crear otro sistema, de escritura y lectura (1977: 44), lo que conlleva desarticular clasificaciones como las de género literario, autor, realidad/ficción, crítica/ficción, la teoría como metodología, lo nacional y lo extranjero.

Cavernícola es el nombre que pone el argentino al escritor que "lee los textos de la tradición, los deglute, los lleva hacia el fondo de la cueva y allí, esculpe un nuevo texto que lo diferencia y que reelabora la biblioteca del continente" (López 2012: 1), y en esta perspectiva realiza una

elección que da por finalizado el boom y que, por su negatividad, se sustrae a la tentación de lo que vendrá en los años posteriores [...]. El texto de Libertella se planta en ese otro lugar, ese lugar imposible, que es el de un tipo de comunidad literaria que opera por desplazamientos de sentido, de salto en salto, hasta alcanzar el estatuto de comunidad negativa, la comunidad de los que no tienen comunidad. (Tabarosky 2010: 44)

En el tránsito de una escritura a otra, es decir, de un libro a otro, Libertella irá transmutando los nombres del escritor:

En otros textos, y también repetidamente, el escritor será cavernícola, un cocinero, un mono, un loro, un químico que anda buscando construir su Dr. Frankestein [...], "un alfil" que "cruza y atraviesa en diagonal [...] la fortaleza de las disciplinas constituidas" (Premat 2021: 98).

41 Estos saltos nominales, el infinito desplazamiento, son rasgos propios de la obra de Libertella, que remueve reiterativa y diferenciadamente los lugares donde acontece la literatura. En esta dirección, en Nueva Escritura en Latinoamérica

Libertella propone algo que vendrá -o que, por lo menos, sería deseable que viniera-: tanto un libro por venir como una comunidad por venir. El conocimiento del libro de Libertella no es especulativo ni contrastable, es proyectivo, es una apelación a la acción, casi un manifiesto crítico-literario, la propuesta de un modo de leer (Pardo 2014: 63).

\section{Las citas y lo común}

En Nueva escritura en Latinoamérica, Libertella comenta La Orquesta de Cristal, novela publicada en 1976 cuyo argumento gira en torno a lo inverosímil, el concierto de una orquesta que no puede ser ejecutado dada su materialidad y el relato de lo que nunca 
acontece ya que el narrador retrasa la acción de manera infinita Libertella destaca la ambigüedad de la novela que se pasea entre la monografía literaria y la crónica entre otros géneros. La novela es protagonizada por Pompiffier, variación del personaje Pompier, suerte de alter ego, o histrión literario de Lihn (Lange 2010).

La Orquesta de Cristal se articula en torno a grupos inexistentes, comunidades que carecen de relato y que son contadas a través de anécdotas superpuestas e infinitas mediante choques de las temporalidades que se despliegan a través de lo que el autor denomina la cháchara, esto es:

[la] teoría lingüística sostenida por Lihn a partir de la lectura de Lacan, se refiere al lenguaje vacío, en este caso de la academia, y en general al lenguaje vacío de la literatura que intenta 'ordenar' el mundo, darle un significado otro a la realidad que enfrenta, al recargamiento de descripciones que pueblan las historiografías clásicas, así como los lenguajes oficiales: cháchara teórica y cháchara de quienes sustentan el poder. El atiborramiento de información en la novela es, como se ha señalado, un atiborramiento que cubre un acto no realizado, marcado por la represión y la irrupción de la policía en el escenario final de la Orquesta (Lange 2019: 79)

Algo similar ocurre en El Arte de la Palabra, protagonizada por Pompier, y enunciada a través de una nomeclatura de géneros literarios, la novela relata la reunión de un grupo de escritores que asisten a un Congreso en la República Independiente de Miranda, espacio imaginario, indefinido geográficamente, atiborrado de lugares comunes, cuyos habitantes apenas dan cuenta de su existencia. El Congreso nunca se realiza y sus participantes casi no hablan entre sí. Se encuentran en un lugar remoto y mantienen absurdas discusiones a través de la palabra escrita, dimes y diretes dignos de una telenovela centroamericana.

Ambas novelas giran en torno a comunidades inexistentes, personajes y espacios fantasmales perdidos en una espera permanente por una reunión imposible, porque no hay lugar para lo común a través de una identidad colectiva. Esa posible identidad no existe, tal como lo manifiesta el despliegue de la cháchara, como anulación de todo sentido.

En "Entretelones técnicos de mis novelas", Lihn se transforma en comentarista de sí mismo, recoge algunas lecturas críticas sobre sus novelas, principalmente las de Libertella. Sobre estas señala: "Muchas de las instancias de mi trabajo están enunciadas en el repertorio que hace H.L. de sus procedimientos" (Lihn 1981: 7).

El encuentro de estas dos escrituras, cruzadas por la lectura mutua y la anécdota, se produce en tanto ambas circulan como comunidad negativa:

Hacia 1974, en La Orquesta de Cristal, puse a prueba a Pompier, un personaje preexistente a las novelas en cuyo reparto figura; quise desplegar y encarnar, por la vía de la materialización de ese fantasma, la sociosis propia de nuestro discurso y decurso histórico. Los primeros comentarios escritos de esta novela, que publico en Derechos de autor, fueron los de Tamara Kamenszai y Héctor Libertella -una pareja formada por una poetisa y un novelista, ambos ensayistas jóvenes, de nacionalidad argentina-. Leyeron los originales en Nueva York y promovieron su publicación en Buenos Aires, donde apareció O.C, en 1976 (Lihn 1981: 6)

Lihn salta del comentario al relato e inscribe la lectura de su novela en una extensión de la misma. A lo largo de este texto, el chileno trabaja con críticas y análisis que se han hecho a su narrativa:

Tengo buenos amigas y amigos que no entienden lo que escribo, y me lo confiesan derechamente. Esto en lo que se refiere especialmente a mis novelas: La Orquesta de Cristal y El Arte de la Palabra. En lo que queda de crítica pública en Chile, las actitudes 
divergen, pero su tendencia es negativa. Hay críticos que me omiten (supongo que no sólo por razones literarias) y otros que, con toda buena voluntad y en cinco frases cortas, celebran mi poesía y deploran la falta de "distancia estética" de mi narrativa, la pobreza de su oscuridad, el despliegue que hago de ella de inteligencia "redactada". [...] El primero, cronológicamente, de esos trabajos, es un capítulo de Nueva Escritura Latinoamericana del novelista y ensayista argentino Héctor Libertella, y el más extenso de un profesor joven de literatura hispanoamericana de la Universidad de Nueva York, el poeta norteamericano George Yúdice; ensayo que he traducido para aprender algo de mí mismo, titulado "Enrique Lihn: Parodia versus Retórica". Quiero agregar algo a esta introducción (y una moraleja relativa: nadie es absolutamente profeta en su tierra). Mis novelas cuentan, en Chile, con lectores numerados. Me sorprenden, incluso, algunos de ellos: tengo aquí lectores insólitos. A estos y a mis amigos que no me entienden, dedico esta conferencia" (1981:1 énfasis añadido)

La ironía de este fragmento al referirse a la crítica y su indiferencia o escasa lectura de sus novelas permite desplegar un modo de comentario interrumpido. El escritor no solo se refiere a la crítica sino que dedica el texto a lectores y amigos "que no me entienden", es decir, cuyo universo significante funciona a la espera de una escritura convencional inexistente.

\section{BIBLIOGRAFÍA}

Antelo, Raúl, “Teoría de la caverna. Los restos de un futuro que vuelve”, Damiani, Marcelo (comp.), El efecto Libertella, Rosario, Beatriz Viterbo, 2010, p. 147- 179.

Avelar, Idelber, Alegorías de la derrota. La ficción postdictatorial y el trabajo del duelo, Santiago, Cuarto Propio, 2000.

Casullo, Nicolás, "Debate sobre el drama de un poeta y una época", Pensamiento de los Confines n⿳o 17, diciembre 2005, Buenos Aires, FCE, p. 83-94.

Damiani, Marcelo (comp.), El efecto Libertella, Rosario, Beatriz Viterbo, 2010.

Duchesne Winter, Juan, Comunismo literario y teorias deseantes: inscripciones latinoamericanas, La Paz, University of Pittsburgh / Plural, 2009.

Gilman, Claudia. Entre la pluma y el fusil. Debates y dilemas del escritor revolucionario en

América Latina, México, FCE, 2012.

Lange, Francisca, "Nadie habla, nadie escribe. Apunte final sobre Lihn \& Pompier", Notas Visuales, Santiago, Pontificia Universidad Católica, Instituto de Estética / Metales Pesados, 2010, p. 81-103.

---, "Una lectura de la Orquesta de Cristal de Enrique Lihn: historia, catástrofe y escritura", Chile desde los Estudios Culturales. Miradas actuales sobre poesía, narrativa y cultura visual, Santiago, UFT, 2019, p.73-99.

Libertella, Héctor, Nueva escritura en Latinoamérica, Caracas, Editorial Monte Avila, 1977.

Lihn, Enrique, “Caso Padilla” Mensaje, 1971a, Santiago de Chile, vol. 199, p 236-239. 
---, "Política y cultura en una etapa de transición al socialismo", La cultura en la vía chilena al socialismo, Santiago, Universitaria, 1971b, p 15-76.

---, La orquesta de cristal, Buenos Aires, Sudamericana, 1976.

---, El arte de la palabra, Buenos Aires, Pomaire, 1980.

---, Sobre el antiestructuralismo de José Miguel Ibañez Langlois. Santiago de Chile, Ediciones del Camaleón, 1983.

---, Derechos de autor, 1981/72, 69 etc. Santiago, Yo Editores, 1981.

Nancy, Jean Luc, La comunidad inoperante, Santiago, LOM / ARCIS, 2000. Traducción de Juan Manuel Garrido.

López, Silvana, "Insistencias y deslizamientos en la escritura de Héctor Libertella”, VII Congreso Internacional de Teoría y Crítica Literaria Orbis Tertuis. Universidad de la Plata, 2012. Web, consultado $07 / 11 / 2017$.

Pinos, Jaime, "La puntada invisible", Horroroso Chile. Ensayos sobre las tensiones políticas en la obra de Enrique Lihn, Santiago de Chile, Alquimia, 2013, p. 57-64.

Pardo, Esteban, Libertella, un maestro de la lecto-escritura: un recorrido, Mar del Plata, Puente Aéreo, 2014.

Premat, Julio, ¿Qué será la vanguardia? Utopías y nostalgias en la literatura contemporánea, Rosario, Beatriz Viterbo, 2021.

Van Rooden, Aukje, "La comunidad en obra. Jean-Luc Nancy en diálogo con Maurice Blanchot: Un desacuerdo tácito”, Revista Pléyade, Volumen IV, nº1, enero-junio 2011, Santiago, Centro de Análisis e Investigación Política CAIP, p. 79-103.

\section{NOTAS}

1. Sus libros anteriores son tres novelas: El camino de los hiperbóreos (1968), Aventuras de los misticistas (1971) y Personas en pose de combate (1975).

2. En "Teoría de la caverna. Los restos del futuro que vuelve", Raúl Antelo analiza pormenores textuales de la contienda (2010: 168-170).

3. Un ejemplo claro de esto es Historia personal del boom, de José Donoso.

4. Como señala Jaime Pinos, el escritor llega a Cuba "con las ilusiones políticas de quien, a inicios de los sesenta, era un militante del partido comunista y aparecía como un entusiasta del castrismo" (2013: 57).

\section{RESÚMENES}

En el campo cultural latinoamericano de las décadas de los sesenta y setenta predomina una noción de comunidad orgánica que se articula en torno a la idea de un proyecto común, la literatura latinoamericana, a la luz de la utopía revolucionaria gatillada por la Revolución Cubana 
y la implosión literaria del boom. Frente a este contexto, se reflexiona sobre el desarrollo de un modo de comunidad inorgánica en los trabajos de Enrique Lihn y Héctor Libertella, y cómo estos se oponen a esos discursos normativos.

Dans le champ culturel Latino-Américain des années 1960 et 1970, prédomine une notion de communauté organique articulée autour de l'idée d'un projet commun, la littérature latinoaméricaine, à la lumière de l'utopie révolutionnaire déclenchée par la Révolution cubaine et l'implosion littéraire du boom. Dans ce contexte, nous analysons une modalité de communauté inorganique dans les œuvres d'Enrique Lihn et d'Héctor Libertella, et à la manière dont ils s'opposent à ces discours normatifs.

Within the Latin American cultural field of the sixties and seventies predominates a notion of organic community articulated around the idea of a common project, the Latin American literature, in the light of the revolutionary utopia activated by the Cuban Revolution and literary boom implosion. Against that background, we reflect into the development of an inorganic community mode in the works of Enrique Lihn y Héctor Libertella and the way they oposse these normative discourses.

\section{ÍNDICE}

Mots-clés: Lihn, Libertella, communauté organique, communauté inorganique, communauté littéraire

Palabras claves: Lihn, Libertella, comunidad orgánica, comunidad inorgánica, comunidad literaria

Keywords: Lihn, Libertella, organic community, inorganic community, literary community

\section{AUTOR}

\section{FRANCISCA LANGE V.}

Universidad Finis Terrae

flange@uft.cl 